\title{
Reflections on the Cultivation of Translation Ability in English Teaching in Higher Vocational Colleges and Practices Study
}

\author{
Yingxiang Zhong \\ Chongqing Youth Vocational and Technical College, Chongqing, 400000, China
}

Keywords: Vocational colleges, English teaching, Translation ability, Practice.

\begin{abstract}
English is a general course of colleges and universities in our country. Under the current background of economic globalization, the cultivation of students' English quality has a great influence on the future development of students. Therefore, in the process of education reform in higher vocational colleges, we should attach great importance to the cultivation of students 'English ability, and provide corresponding protection for the strengthening of students' comprehensive quality. This paper analyzes the measures of cultivating students 'English translation ability in English teaching in vocational colleges, hoping to provide good support for the cultivation of English students' English translation ability.
\end{abstract}

\section{Introduction}

The main goal of English teaching in vocational colleges is to hope that through the implementation of relatively systematic application of education and guidance to students to enable students to master a certain basic knowledge and skills in English, and have the appropriate English listening, speaking, reading and writing ability to ensure that To achieve the ability of students in English education and translation skills for students to lay the foundation for future career development. However, in the current practice of English teaching in vocational colleges in our country, the teachers' training ability of students' English translation is neglected, and even some teachers do not offer English translation courses, which leads to the great restriction of students' English translation ability training. The strengthening of the overall quality has had a serious adverse effect. Therefore, it is necessary to explore the application of teaching reform measures in the new period, to strengthen the emphasis on English translation teaching, and to create good conditions for students' English translation ability.

\section{The Importance of Cultivating Students' English Translation Ability}

In the new period, the importance of English translation in the practice of English teaching in vocational colleges is mainly due to the students' English translation ability has become the inevitable requirement of social development and international exchange in the era of economic globalization, and also the vocational colleges The English education department to promote the optimization of English teaching the necessary means of development, so vocational colleges based on their own technical skills training objectives, should strengthen the ability of students to develop language skills for students to enhance the level of translation skills to provide appropriate protection, only In this way, vocational colleges can provide high-quality English translation talents for the society, and provide corresponding talent support for the comprehensive development of China's international economic activities. In addition, the status quo of the employment situation of college students in higher vocational colleges also makes corresponding demands on the cultivation of students' English translation ability. In the current fierce competition in the job market, higher vocational colleges should further strengthen the employment competition of the graduates Ability, students should be 
able to implement English translation ability education, effective training of students' translation skills, for students after graduation to create a good condition for smooth employment. It can be seen that the new period has a certain practical significance for the effective cultivation of students' English translation ability in vocational colleges and is worthy of in-depth research and exploration.

\section{The Current Situation of English Translation Teaching in Higher Vocational Colleges}

In the process of organizing the teaching activities, the English teachers of vocational colleges in our country have carried on the appropriate reform and innovation to the English teaching, hoping to cultivate the students 'interest in English learning and improve the students' English Learning ability, laying the foundation for the cultivation of students' English translation ability. However, through the current situation of English teaching in vocational colleges and found that teaching reform is not complete, there are still some problems in teaching practice, which seriously limits the improvement of teaching quality and is not conducive to the cultivation of students' English translation ability. In particular, the existing problems in English translation teaching in higher vocational colleges are mainly in the following aspects: First, the English foundation of students in vocational colleges is weak and the English foundation and learning ability of different students are different, In the absence of correct teaching theory guidance, teachers are difficult to combine the actual situation of students to implement targeted teaching guidance, which leads to the overall teaching effect is relatively poor, is not conducive to the cultivation of students' English translation ability. On the one hand, students in the process of learning English translation knowledge by the inertia of the mode of thinking is likely to appear in the phenomenon of English, that is, although still using English vocabulary to translate, but not consciously applied the Chinese grammatical structure, seriously affecting the correct translation Sex. In the process of translating “人山人海”, students do not pay attention to the particularity of idiom translation, but rather translate it into "people mountain people sea.", Although it can be seen from the surface of the meaning of words, but the translation of aesthetic effects Also neglected, is not conducive to the effective cultivation of students' translation ability. On the other hand, students in the process of translation there is a customary list of the words of real words, can not determine the application of auxiliary words and prepositions, resulting in the translation of the structure is not complete, and even can not clearly convey the meaning of translation. In addition, the lack of flexibility in translation is also a more common problem, because the students master the English words less, to a certain extent, students can not accurately use the relevant words when translating, can only use the only vocabulary for blunt translation, serious impact The translation effect [1]. Secondly, teachers in the teaching of English translation of the cultural differences first ignored, not to explain the differences between students of Eastern and Western cultures, resulting in some students in the translation process because they do not understand the wrong translation of Western culture, seriously affect the translation of students, The cultivation of students' translation ability also has some bad influence. As in the English language system, by the special cultural background of English, "the black sheep" is generally used to express the meaning of the black sheep. However, students do not understand the case of Western culture, seriously affect the understanding of students, limiting students' learning outcomes. Therefore, in the process of actively exploring the reform of English teaching, the English teachers in vocational colleges should further strengthen the emphasis on translation teaching, explore the optimization of translation teaching, and effectively cultivate students' English translation ability.

\section{Measures of Cultivating Students' English Translation Ability in English Teaching in Higher Vocational Colleges}

The cultivation of students 'English translation ability in English teaching in vocational colleges is not an easy task. It is necessary to cultivate translation teaching through English teaching, combine different contents to form differentiated teaching measures, cultivate students' To ensure that students learn the results. 


\section{Cultivating Students' Translation Ability in English Intensive Reading}

English intensive teaching is an important course of English teaching in vocational colleges, and the cultivation of students 'translation ability in English intensive teaching can help to give full play to the auxiliary teaching of intensive reading teaching and promote the students' ability of translation.

To strengthen the learning of vocabulary to lay the foundation for the cultivation of students' translation ability

English vocabulary is the basis for students to learn the relevant English knowledge, only students have a certain accumulation of English vocabulary, can follow the teacher's teaching to explain the completion of English learning tasks, to achieve good English learning effect. Therefore, in the intensive English translation teaching, teachers should also pay attention to the cultivation of students' vocabulary ability, enrich the accumulation of students' vocabulary, and lay a solid foundation for the enhancement of students' translation ability. In the specific operation, teachers can introduce different vocabulary learning methods, such as image memory and associative memory, etc., to ensure that students learn English vocabulary [2].

For example, in the process that the teacher explains the word "bless", the teacher should first let the students clear their basic meaning of blessing, blessing. On this basis, teachers use the association learning method to extend the word to the phrase, explain to the students "be blessed with" application, and for example analysis, the students master their specific application, the teacher with specific examples to guide students to translate, such as asking students to translate "这座小镇有着 天赐的资源", students shall use the phrase "be blessed with" , can easily be translated as "This town is blessed with rich natural resources", and in the course of the application of students The meaning of the word can also form a more profound understanding.

Cultivating Students' Translation Ability with Original Understanding and Sentence Processing

In the practice of teaching students to cultivate the ability to just understand the meaning is not enough, students want to enhance their own translation literacy, in the process of accepting English teaching should also be combined with reading comprehension and special sentence processing to translate skills to strengthen training, To ensure their own translation ability can be well trained for students to further study the relevant knowledge of English to provide the appropriate protection. Such as "Children are kept busy with candies they believe to be brought to them by Fairy." This long sentence, students in the learning process often can not form a correct understanding, so teachers can guide students to grasp the structure of the long sentence on the basis of To analyze the translation of long sentences, and then clear the structure of different long sentences and translation points [3]. On this basis, teachers in order to deepen the memory of students, but also for students to provide similar structure of the sentence requires students to analyze the sentence structure, and then translation, such as "父亲们忙于他们认定是上天给予他们的养家责任" to ensure the translation of students Ability to be effectively enhanced training

\section{In the practice of teaching students to cultivate the ability to translate}

The ability of students 'translation is the category of students' application of English knowledge system. Therefore, in order to ensure the translation teaching effect, the students can complete the relevant translation tasks in combination with the actual requirements after graduation. In the course of teaching, teachers should also organize students to participate in translation practice training, The students' ability to implement effective education and training.

Combined with job requirements design practice teaching content

In the English textbooks of higher vocational colleges, the translation content is generally relatively small, only the short sentences translation, translation or text translation, etc., combined with teaching materials to explain the students' ability to translate can not be effectively cultivated, translation practice Ability will be greatly limited [4]. Therefore, in the teaching of translation, teachers combined with the future job requirements of students can reasonably choose the content of translation teaching, the implementation of targeted intensive training of students to promote students' translation skills to be well developed, such as students for business English learning needs, 
teachers In the process of cultivating students' ability of translation, we can try to combine translation work with documents, business letters and customs declaration work. Students should also guide students to develop their own translation product brochures. Operational aspects of the content, and effectively enhance the teaching targeted. In this way, according to the needs of students in the implementation of professional training students, students of professional translation ability can be further strengthened, the students in-depth study of relevant English knowledge have a positive impact, but also help to promote the future development of students.

Combined with the task of organizing the organization of translation teaching

In the practice of translation practice, the teacher can strengthen the training of the students in the practice of translation practice. It can divide the content of the translation teaching into multiple learning tasks, and then let the students learn the students' translation skills on the basis of the task of translation practice. In this process, it should be noted that the translation tasks set by teachers must be hierarchical, that is, different levels of students to complete different learning tasks, and gradually to cultivate the ability to translate. So that students' ability to translate can be significantly improved. In the specific operation, teachers in the design and practice of translation tasks can be selected in the process of specific teaching topics, such as "warm home", and then around this theme set up a variety of types of translation tasks, such as the warm home dialogue translation, home Translation of bills, translation of letters, etc., students in the process of continuing to complete the translation process not only to develop their own translation skills, but also to master the different text of the translation, to promote students' English translation practice application ability to get all-round training. Another example is the "business activities" as the theme of the translation task, the teacher can set a reasonable set of foreign trade business documents preparation, booking hotels, business letters, meeting notice and many other translation tasks, students involved in the translation task practice In the process not only completed the training of translation skills, but also to the future work of translation to form a preliminary understanding, and master the work of the relevant documents translation skills for students to lay a solid foundation for future employment [5]. It can be seen that translation practice plays an extremely important role in cultivating students 'translation ability. Teachers must strengthen the importance of practical training and provide good support for the cultivation of students' translation ability and the enhancement of English knowledge application ability.

\section{Conclusions}

To sum up, the cultivation of students 'English translation ability in vocational colleges is related to the future development of students and the improvement of the quality of personnel training in higher vocational colleges. Therefore, higher vocational colleges should further strengthen the emphasis on cultivating students' translation ability , And actively explore the optimization of students' ability to translate the translation skills for the gradual strengthening of students to provide appropriate protection, the only way in the vocational college English teaching practice to give full play to the important role of English translation teaching, students of English Quality can be well trained, can effectively promote the future development of students better.

\section{References}

[1] Zhang Ting.On the Cultivation of Translation Ability in English Teaching in Higher Vocational Colleges, Scientific and technical information, 2012(36):236.

[2] Wang Lijuan, Chen Xuanrong, Luo Huan.On the Reform of Translation Courses for English Majors in Higher Vocational Colleges from the Perspective of Curriculum Connotation, Journal of Kaifeng Institute of Education, 2014(9):150-151.

[3] Dan Yinli.A Brief Analysis of Translation Exercises in English Intensive Reading in Higher Vocational Colleges, Testing and evaluation, 2016(5):59. 
[4] Liu Limin.The Enlightenment of Translation Competence Research on English Translation Teaching in Higher Vocational Colleges, Journal of Wenzhou Vocational and Technical College,2013,13(3):89-92.

[5] Gan Caihong.The Construction and Practice of English Translation Teaching Model in Higher Vocational Education Based on the Translation of Primary Tools, Journal of Yanbian Education College,2015,29(1):44-47. 